\title{
The luckiest generation
}

$\mathrm{I}_{\mathrm{f}}^{\mathrm{t}}$

t was the end of the sixties, the start of the seventies. The flower power generation was aging and trading in their vans for family cars, Nixon was in the White House, and we were plastic surgery residents.

Our road to that place had been long though we were barely aware of it. Born before or during World War Two we represented the hope of the end of the great Depression our parents hope - and if our parents were the best generation, we were the luckiest generation. Lucky to be born and grow up in a time of prosperity and expansion, when careers were expanding and when it was easy to get into medical school with average marks. We all could have done better academically but we didn't see the point as we were having too much fun (there's no such thing as too much fun). We were shaped by music, cars and television. We transitioned from Glen Miller to Bill Haley and the Comets, Chubby Checker and the Twist, the great Satchmo, the Beatles and Elvis. Our cars were prewar art deco monsters, Volkswagens and rocket ships with fins. Hugh Heffner and John F Kennedy were our gurus. We were idealists, and if not exactly libertines, much more liberated than our parents. In October, 1962 at the time of the Cuban Missile Crisis, we were certain we would be at war within the week. I cannot describe the relief we all felt when the crisis was defused. That event alone made us peacemakers. We were interested in the world, as we knew we could not sit in isolated smugness believing that events would pass us by; we had grown up with the cold war and the arms race - to us, Dr Strangelove was real and we needed ironic comedy as a way of looking at the lunacy of fanaticism. The great Peter Sellers spoke for us and we imitated his accents as we slipped from one character to another. We developed a great distrust of very serious people for we knew that those with a mission, especially those who believed there was only one way of doing things, were inherently dangerous.

A lot has been written about the drug culture, most of it hype. I can assure you that those of us who were medically trained only experimented with alcohol and caffeine, and usually one binge was enough. Our pharmacology training prohibited us from experimenting with anything else. There was no way we were going to let psychotropic drugs affect our brains, not after we learned how potent pure drugs were, not to mention drugs brewed in somebody's garage. We might have talked freely, but we were not foolish; after all, we were much like our parents' generation.

Medical school was where we grew up. We were enthralled by the idea of becoming physicians. It was egocentric and idealistic. In six years, a raw high school graduate could become a white-coated doctor with a pipe and stethoscope and, we hoped, a chick magnet. (In those days we carried our stethoscopes in our pockets, not around our necks.) My problem was that I found the lectures repetitive, narrow and stultifying. It was more than that; driven by a need to find heros, I found only my anatomy professor (for his Scottish humour) and my surgery professor (for his encyclopedic knowledge and war record) objects of my admiration. There was too much drudgery and not enough passion. I was

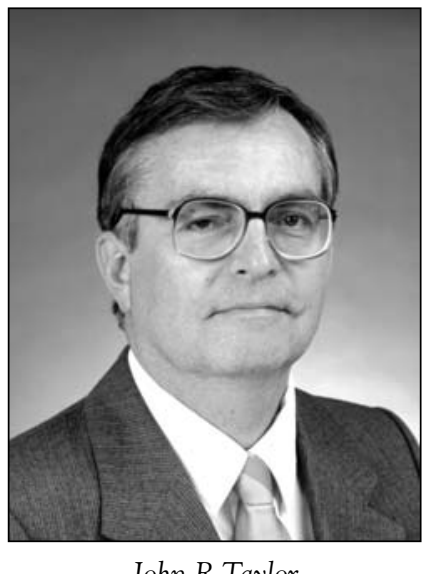
starting to understand it was the teachers job to show the student how easy everything was and assume the student had the mental equipment to understand; but it was the repetition that finally got me; I was starting to have a glimmer of a great truth; just give me the concepts, the details come later and to understand by doing.

As Jack Webb said on Dragnet, "just the facts, Ma'am.”

Even as medical students, we could see the difference between the medical and the surgical life, and the surgeons in embryo were being drawn toward surgery as much for it's action and decisiveness as anything else. We wanted to live large and this was how we were going to do it.

I think we chose our specialties by image more than anything else - what we wanted to become; how we saw ourselves in the future. We were lucky because we could do anything we wanted. The future was open to us. Unlike today, we could try family practice for a while then specialize later if we wanted.

Once we started training, we were junior assistants to the great surgeons. We had to know our stuff, work hard and keep our heads down. Now in our late twenties, we were almost all married by this time and many of us had young families. We worked and stayed in the hospital every second night and every second weekend. Our spouses were the real heros of our training and the adjustment and loneliness was difficult for all of us, and a source of not a few divorces. The system made us work hard to get training over with so we could get on with life. And how we studied. On our nights off, instead of playing with the kids, we went to the basement and studied. We were young and could do it, but it was tough. We had great seminars. One evening every two weeks and every Saturday morning we covered our work in the form of topics or fellowship exam questions. It wasn't like medical school at all, it was way better. 
In the operating room, we were asked what we thought. We were seldom told what to think, and our surgeon teachers were generally kind. We were taught the Socratic method before problem-based learning became trendy. We learned early never to make up answers. If we did, the response would be a loud "HA!" or a kinder, "most people wouldn't have said that, actually."

We made great life long friends for there is nothing like mutual hardship to cement a bond. We learned to joke and mimic as a way to change roles and release tension, but always after the boss had scrubbed out. We learned to do difficult things and give bad news in a human way. When it was time to wake the patient up we'd look at the anesthetist, a doctor we'd gained great admiration for and say, "run for the helicopters" (after the African Show in which the TV personality gave the elephant the antidote and ran to avoid getting trampled as the giant beast staggered to its feet). "He lives, Igor" was another favorite.

We were correct without being political.

We didn't know if we had what it took to become surgeons when we started and nobody ever told us, we just did our best and tried to survive. There must have been a day when we knew we were going to make it, but I was never aware of it, we were too busy to think that way. It was as if we started as them and us, and imperceptibly we became us. I remember one day when I must have been daydreaming, sighing or looking out the window and the Great One told me, "Taylor, always remember, if you don't want to do this there are eleven others eager to take your place."

That woke me up.

And the minds we were exposed to! They were great, and many were intuitive and lateral thinkers. They were disciplined, optimistic, punctual and they always cut to the chase. They accepted us as the next generation and when they knew we were serious students they would let us into their worlds as equals. Many became life long friends. They had many dimensions, but we were too young to be aware of more than a few. We learned a lot of manual dexterity tricks and how to use various instruments, but it was more thinking based than manual dexterity. One did not need the talent of a great piano player; more the thinking of a chess player and the ability to shift ideas around. Later, when internal medicine was called intellectually based and surgery procedurally based, we just laughed. We knew where the intellects were and didn't bother explaining it to anyone.

Years later a close surgical friend said to me, "you know, we had a military training." This had not occurred to me but I knew immediately it was true. Many of our teachers served in the military, achieving high ranks. When they chose us for training they were choosing junior officers who could take command some day. Our training was military to see how tough we were, and whether we could tolerate battlefield conditions, or crack under the strain. They wanted to know if we could focus, achieve, and understand the concepts, and we did because they taught us to do this. We also did it because we admired and respected them for who they were. They were decisive and confident and had solid achievements they didn't talk about much. They had a quiet pride.

We were worried about the fellowship exams because we did not want the humiliation of failing, and we needed to move to the next stage as soon as we could. Our families needed us. Our training was an indulgence allowed us, but we could not allow it to go on forever. We need not have worried. Every day and every seminar was preparation for our examinations. Every question in the operating room was getting us ready, and when the exam time came, the questions were fair and aimed mainly to assure we were fit for independent practice. We were very proud of our achievement - the FRCS(C); I have never been as proud of anything before or since, except my family.

That is how I feel to this day. I never had to go to war due to the sacrifices of others. I didn't choose my generation none of us ever do. I was fortunate to be born when I was, and have others encourage me.

We are members of the luckiest generation. That's why we try to give some of that luck to others along the way.

John R Taylor 